\title{
Effect of increasing dietary nonfiber carbohydrate with starch, sucrose, or lactose on rumen fermentation and productivity of lactating dairy cows
}

\author{
X. Gao and M. Oba ${ }^{1}$ \\ Department of Agricultural, Food and Nutritional Science, University of Alberta, Edmonton, AB, Canada T6G 2P5
}

\begin{abstract}
The objective of this study was to investigate effects of increasing dietary nonfiber carbohydrate (NFC) with starch, sucrose, or lactose on rumen fermentation, volatile fatty acid absorption, and milk production of lactating dairy cows. Twenty-eight multiparous, lactating Holstein cows $(141 \pm 50 \mathrm{~d}$ in milk; $614 \pm 53 \mathrm{~kg}$ of body weight) including 8 ruminally cannulated cows were used in this study. Cows were assigned to 4 dietary treatments in a $4 \times 4$ Latin square design with 21 -d periods. The treatments were control $[27 \%$ starch and $4 \%$ sugar on a dry matter (DM) basis], a high-NFC diet by increasing dietary starch content (STA; $32 \%$ starch and $4 \%$ sugar on a DM basis), and 2 more high-NFC diets by increasing dietary sugar content $(27 \%$ starch and $9 \%$ sugar on a DM basis) in which sucrose (SUC) or lactose (LAC) was supplemented. Dry matter intake was greater for cows fed high-NFC diets compared with control diet (27.1 vs. $26.3 \mathrm{~kg} / \mathrm{d}$ ), but rumen $\mathrm{pH}$ and milk production did not differ between cows fed control and high-NFC diets. However, cows fed high-disaccharide diets had lower mean rumen $\mathrm{pH}$ than those fed STA diet (6.19 vs. 6.32). Although molar proportion of butyrate was greater for high-disaccharide treatments than STA treatment (15.2 vs. $13.7 \mathrm{~mol} / 100 \mathrm{~mol})$, absorption rate of volatile fatty acid in the rumen was not affected by treatment. In addition, cows fed high-disaccharide diets had higher energy-corrected milk yield than cows fed STA diet (39.6 vs. $38.0 \mathrm{~kg} / \mathrm{d})$. Dry matter intake did not differ between cows fed 2 high-disaccharide diets. Although cows fed the SUC diet had lower molar proportion of butyrate in the rumen compared with those fed the LAC diet (14.4 vs. $15.9 \mathrm{~mol} / 100 \mathrm{~mol}$ ), the SUC diet did not decrease rumen $\mathrm{pH}$. In addition, cows fed the SUC diet had lower nutrient digestibility of organic matter than did those fed the LAC diet (59.7 vs. $64.4 \%$ ), but milk component yields did not differ between the 2 high-disaccharide diet treatments. The
\end{abstract}

Received May 26, 2015.

Accepted September 23, 2015.

${ }^{1}$ Corresponding author: masahito.oba@ualberta.ca results of the present study suggested that partially replacing dietary starch with disaccharides increased DM intake and energy-corrected milk, although rumen $\mathrm{pH}$ decreased for high-disaccharide diets, and that the rumen $\mathrm{pH}$ responses cannot be attributed to difference in absorption rate of volatile fatty acids in the rumen. In addition, type of sugars affected nutrient digestibility and rumen fermentation, but the effects were not large enough to affect rumen $\mathrm{pH}$ and milk production.

Key words: disaccharide, rumen fermentation, volatile fatty acid absorption, nutrient digestibility

\section{INTRODUCTION}

Increasing dietary NFC is a common diet-formulation approach to maximize milk production of highproducing dairy cows. Starch is the primary source of NFC in the diets of lactating dairy cows (NRC, 2001), but feeding more starch in dairy diets may also increase the risk of ruminal acidosis, which is associated with decreased feed intake, liver abscesses (Nagaraja and Lechtenberg, 2007), milk fat depression (Kleen et al., 2003), and laminitis (Nocek, 1997). Because the demand and cost of cereal grains has increased in the last decade, partial replacement of grains with high-sugar by-products becomes a diet-formulation approach to decrease feed costs while maintaining high milk yield. Sugars are water-soluble carbohydrates that can be fermented easily and quickly in the rumen (Oba, 2011), consisting of monosaccharides (glucose, fructose, and galactose) and disaccharides (sucrose, maltose, and lactose). Previous research indicated that partial substitution of dietary starch with sugars often increased DMI (Broderick and Radloff, 2004; Broderick et al., 2008; Penner and Oba, 2009) and milk fat yield (Broderick et al., 2008; Penner and Oba, 2009). Therefore, increasing dietary NFC content by feeding more sugars can be a viable option to maximize energy intake and productivity of lactating dairy cows. In addition, a recent review (Oba, 2011) showed that rumen $\mathrm{pH}$ did not decrease (McCormick et al., 2001; DeFrain et al., 2004; Broderick et al., 2008), but even increased (Chamberlain et al., 1993; Heldt et al., 1999), when sugar was used to replace a part of dietary starch, even 
though the hydrolysis and fermentation rate of sugar in the rumen is faster than starch (Sniffen et al., 1992). In vitro studies indicated that feeding sugar could result in increased molar proportion of butyrate in the rumen (Vallimont et al., 2004; Ribeiro et al., 2005), and Malhi et al. (2013) reported that ruminal butyrate infusion increased the ruminal epithelia growth and absorption capacity of VFA in the rumen. The increased capacity of ruminal epithelia to uptake acetate and butyrate is positively related to rumen $\mathrm{pH}$ (Penner et al., 2009a). As such, we hypothesized that increasing dietary NFC by feeding more disaccharide instead of starch would not decrease rumen $\mathrm{pH}$ by increasing the rate of VFA absorption.

Whey and molasses are high-sugar by-products commonly included in diets for dairy cows. Whey is a byproduct of cheese manufacturing containing about $70 \%$ lactose on a DM basis (Oba, 2011), and molasses is a by-product of refining sugarcane or sugar beets into sugar containing mostly sucrose. In order to use these high-disaccharide by-products efficiently, it is necessary to understand specific effects of feeding sucrose or lactose on rumen fermentation and animal performance. Weisbjerg et al. (1998) reported that the hydrolysis rate of sucrose is faster than that of lactose, and Sutton (1968) showed that glucose and fructose ferment faster than galactose. Therefore, effects of feeding sucrose and lactose on rumen fermentation and animal performance are expected to be different. Previous studies evaluated effects of partial replacement of dietary starch with sucrose (Broderick et al., 2008) or lactose (DeFrain et al., 2004) on rumen fermentation and animal performance. However, because of the different basal dietary ingredients, forage-to-concentrate ratio, and sugar inclusion rate, it is difficult to compare specific effects of feeding sucrose and lactose on rumen fermentation and animal productivity for those previous studies.

The objective of this study was to investigate the effect of increasing dietary NFC content with starch, sucrose, or lactose on rumen fermentation, VFA absorption, and milk production of lactating dairy cows.

\section{MATERIALS AND METHODS}

All experimental procedures used in this study were approved by the University of Alberta Animal Care and Use Committee for Livestock and conducted according to the guidelines of the Canadian Council of Animal Care (Ottawa, Ontario, Canada).

\section{Animals, Diets, and Experimental Design}

Twenty-eight multiparous, mid-lactating Holstein cows (141 \pm 50 DIM; $614 \pm 53 \mathrm{~kg}$ of BW; mean $\pm \mathrm{SD}$ ) including 8 ruminally cannulated cows were used in this study. Cows were randomly assigned to 1 of 4 dietary treatments in a replicated $4 \times 4$ Latin square design balanced for carryover effects. Each period consisted of a 17-d diet adaptation period and a 4-d data and sample collection period. The treatments were control (CON; $27 \%$ starch and $4 \%$ sugar on a DM basis; Table 1), a high-NFC diet in which dietary starch content was increased by replacing beet pulp in the CON diet with corn grain (STA; 32\% starch and $4 \%$ sugar on a DM basis), and 2 more high-NFC diets in which dietary sugar content was increased by replacing beet pulp in the CON diet with $5.5 \%$ of sucrose (SUC; $27 \%$ starch and $9 \%$ sugar on a DM basis) or lactose (LAC; $27 \%$ starch and 9\% sugar on a DM basis). All experimental diets were formulated according to the NRC (2001) to meet or exceed the nutritional requirements for a 650 $\mathrm{kg}$ cow producing $40 \mathrm{~kg} / \mathrm{d}$ of milk with $3.5 \%$ milk fat and $3.2 \%$ milk protein, and formulated for similar CP concentrations.

Cows were housed individually in tie-stalls bedded with wood shavings, fed the experimental diets as a TMR once daily at $0800 \mathrm{~h}$, and had free access to water. Feed was offered at 105 to $110 \%$ of actual feed intake of the previous day. The amounts of feed offered and refused were recorded daily during sample collection periods. Samples of feed ingredients and orts were collected daily during sample collection periods and composited by period for feed ingredients and by period and cow for orts. The DM concentration of barley silage was determined, by drying samples in a forced-air oven at $55^{\circ} \mathrm{C}$ for $48 \mathrm{~h}$, twice weekly, and as-fed proportions of feed ingredients were adjusted if necessary. Cows were weighed after the morning milking but before the feeding on 2 consecutive days immediately before the start of the experiment. Cows were milked twice daily at 0400 and 1500 h. Milk was sampled from both a.m. and p.m. milkings on d 18, 19, and 20 of each period of the study.

\section{Rumen $\mathrm{pH}$ and Rumen Fermentation}

Rumen $\mathrm{pH}$ was measured in the ventral sac every $30 \mathrm{~s}$ continuously for $72 \mathrm{~h}(\mathrm{~d} \mathrm{18}, 19$, and 20) in each experimental period using the $\mathrm{pH}$ measurement system evaluated by Penner et al. (2006). Minimum, mean, and maximum $\mathrm{pH}$, and duration and area below $\mathrm{pH} 5.8$ were determined for each cow daily and averaged over 72-h periods. Similarly, DMI was determined daily for each cow on d 18, 19, and 20 and averaged over 72-h periods. These data were used to determine acidosis index (area under pH 5.8 divided by DMI; Penner et al., 2009c) to assess the severity of SARA normalized for DMI. 
Table 1. Ingredient and analyzed chemical composition of the experiment $\operatorname{diets}^{1}$

\begin{tabular}{lcccc}
\hline Item & CON & STA & SUC & LAC \\
\hline Ingredient, \% of DM & & & & \\
Barley grain, rolled & 23.5 & 23.5 & 23.5 & 23.5 \\
Barley silage $^{2}$ Canola meal & 35.6 & 35.6 & 35.7 & 35.7 \\
Corn grain, rolled & 5.31 & 5.13 & 6.65 & 6.65 \\
Corn gluten meal & 15.2 & 22.2 & 15.5 & 15.5 \\
Heat-processed soybean meal ${ }^{3}$ & 4.35 & 4.35 & 4.35 & 4.35 \\
Mineral and vitamin mix ${ }^{4}$ & 5.26 & 5.26 & 5.26 & 5.26 \\
Vegetable oil & 1.87 & 1.87 & 1.87 & 1.87 \\
Beet pulp & 1.83 & 1.52 & 1.70 & 1.70 \\
Lactose & 7.00 & - & - & - \\
Sucrose & - & - & 5.52 \\
Nutrient composition & - & $0.57^{5}$ & 5.52 & - \\
DM, \% & 54.4 & 53.7 & 54.2 & 54.0 \\
CP, \% of DM & 16.8 & 17.2 & 17.0 & 17.0 \\
NDF, \% of DM & 28.4 & 26.2 & 26.7 & 26.1 \\
Forage NDF, \% of DM & 15.6 & 15.6 & 15.6 & 15.6 \\
Starch, \% of DM & 27.8 & 31.8 & 27.1 & 27.4 \\
Sugar, \% of DM & 4.60 & 4.50 & 9.15 & 8.60 \\
\hline 1CON & & & \\
\hline
\end{tabular}

${ }^{1} \mathrm{CON}=$ control diet $(27 \%$ starch and $4 \%$ sugar on a DM basis); STA $=$ a high-NFC diet in which dietary starch content was increased by replacing beet pulp in the CON diet with corn grain $(32 \%$ starch and $4 \%$ sugar on a DM basis); $\mathrm{SUC}=$ a high-NFC diet in which dietary sugar content was increased by replacing beet pulp in the CON diet with $5.5 \%$ of sucrose ( $27 \%$ starch and $9 \%$ sugar on a DM basis); LAC = a high-NFC diet in which dietary sugar content was increased by replacing beet pulp in the CON diet with lactose $(27 \%$ starch and $9 \%$ sugar on a DM basis).

${ }^{2}$ Barley silage: $31.0 \% \mathrm{DM}, 12.4 \% \mathrm{CP}, 48.1 \% \mathrm{NDF}$, and $12.1 \%$ starch.

${ }^{3}$ AminoPlus (Ag Processing Inc., Omaha, NE).

${ }^{4}$ Contained $11.6 \% \mathrm{Ca}, 3.39 \% \mathrm{P}, 18.0 \% \mathrm{Na}, 27.8 \% \mathrm{Cl}, 6.77 \% \mathrm{Mg}, 0.24 \% \mathrm{~S}, 0.04 \% \mathrm{~K}, 2,447 \mathrm{mg} / \mathrm{kg}$ of $\mathrm{Fe}, 551$ $\mathrm{mg} / \mathrm{kg}$ of Cu, $1,054 \mathrm{mg} / \mathrm{kg}$ of Mn, $13.0 \mathrm{mg} / \mathrm{kg}$ of Co, $842 \mathrm{mg} / \mathrm{kg}$ of Zn, $8.23 \mathrm{mg} / \mathrm{kg}$ of Se, $24.7 \mathrm{mg} / \mathrm{kg}$ of I, 504 $\mathrm{kIU} / \mathrm{kg}$ of vitamin $\mathrm{A}, 51.3 \mathrm{kIU} / \mathrm{kg}$ of vitamin $\mathrm{D}$, and $1,651 \mathrm{IU} / \mathrm{kg}$ of vitamin $\mathrm{E}$.

${ }^{5}$ Sucrose was added to the STA diet to make dietary sugar content similar between CON and STA diets.

Rumen fluid was collected from cranial, ventral, and caudal sacs and then combined and strained through a perforated screen (Peetex, Sefar Canada Inc., Scarborough, ON, Canada; pore size $=355 \mu \mathrm{m}$ ) every $9 \mathrm{~h}$ over a 72-h period on d 18, 19, and 20 of each experimental period. The samples were centrifuged at $3,000 \times g$ at $4^{\circ} \mathrm{C}$ for $20 \mathrm{~min}$ immediately after collection, and the supernatants were stored at $-20^{\circ} \mathrm{C}$ until analysis. Rumen fluid samples were composited to yield one sample per cow per period for further analysis.

Ruminal fluid samples were analyzed for VFA profile by gas chromatography according to the method described by Khorasani et al. (1996). Rumen $\mathrm{NH}_{3}-\mathrm{N}$ concentration was determined as described by Fawcett and Scott (1960) using a plate reader (SpectraMax 190, Molecular Devices Corp., Sunnyvale, CA).

\section{Ruminal VFA Absorption}

Ruminal VFA absorption rate was estimated on d 21 of each experimental period using Co-EDTA as a fluid passage marker (Uden et al., 1980) and n-valeric acid as an indicator of VFA clearance from the rumen (Resende et al., 2006). At $4 \mathrm{~h}$ after feeding, each cannulated cow received a $2.5-\mathrm{L}$ solution containing $300 \mathrm{~g}$ of n-valeric acid (VWR International, Edmonton, AB, Canada) and $125 \mathrm{~g}$ of Co-EDTA buffered to $\mathrm{pH} 6.2$ with $\mathrm{NaOH}$. The solution of Co-EDTA and n-valeric acid was thoroughly mixed by hand into the ruminal contents. An initial rumen fluid sample was collected immediately before the marker dose (time 0 ), and subsequent samples were collected at $30,60,120,180,360$, 720 , and 1,080 min after the dose. Individual samples of ruminal fluid were analyzed for valeric acid concentration as described previously and for Co concentration using atomic absorption (AA240FS, Varian, Palo Alto, $\mathrm{CA}$ ).

Time zero was used as baseline concentration of $\mathrm{Co}$ to correct concentrations measured at each individual time point (i.e., 30, 60, 120, 180, 360, 720, and 1,080 min relative to dosing). Because the dosing time was 4 $\mathrm{h}$ after feeding, concentration of n-valeric acid at time zero was not necessarily lowest. Therefore, the lowest concentration rather than concentration at time zero was used as the baseline concentration of n-valeric acid to correct concentrations measured at other time points. The exponential rate of decay for the ratio of n-valeric acid and Co was calculated as described by Resende Júnior et al. (2006) using the nonlinear model procedure of JMP (version 11.0, SAS Institute Inc., 
Cary, NC) using the equation $Y_{t}=Y_{0} \times e^{-k t}$, where $Y_{t}=$ concentration at a given time, $Y_{0}=$ baseline concentration, $k=$ fractional rate of clearance, and $t=$ sampling time, hours.

\section{Apparent Total-Tract Digestibility}

Fecal samples were collected from the rectum every 9 h over a 72 -h period on d 18, 19, and 20 of each experimental period (at the same time as rumen fluid collection). Samples were composited by cow and period. Period composites of feed ingredients, orts, and feces were dried in a forced-air oven for $72 \mathrm{~h}$ at $55^{\circ} \mathrm{C}$ to determine DM concentrations. Dried samples were then ground to pass through a 1-mm screen using a Wiley mill (Thomas-Wiley, Philadelphia, PA) for chemical composition analysis. The samples were analyzed for concentrations of DM (AOAC International, 2002; method 930.15), OM (AOAC International, 2002; method 942.05), NDF (Van Soest et al., 1991), starch (Hall, 2009), sugar (Dubois et al., 1956), and CP (AOAC International, 2000; method 990.03) by Cumberland Valley Analytical Services (Hagerstown, MD). Indigestible NDF was used as an internal marker to calculate the apparent totaltract digestibility (Cochran et al., 1986). The indigestible NDF concentration was determined for ingredient, orts, and fecal samples by placing $2 \mathrm{~g}$ of each sample into a nitrogen-free polyester bag $(5 \times 10 \mathrm{~cm}$, pore size $=50 \mu \mathrm{m}$; R510, Ankom Technology, Macedon, NY). Bags were incubated in triplicate in the rumen of a nonlactating cow fed a 100\%-forage diet for $120 \mathrm{~h}$.

\section{Blood Collection}

Blood samples were collected every $18 \mathrm{~h}$ over a 72 -h period (d 18, 19, and 20) in each experimental period from the coccygeal vessels into tubes containing sodium heparin (Fisher Scientific Company, Nepean, ON, Canada). Samples were centrifuged at $3,000 \times g$ at $4^{\circ} \mathrm{C}$ for 20 min immediately after collection, and plasma was harvested and stored at $-20^{\circ} \mathrm{C}$ until analysis. Plasma samples were composited to yield one sample per cow per period for further analysis.

Plasma samples were analyzed for glucose concentration using a glucose oxidase/peroxidase enzyme (Sigma, St. Louis, MO) and dianisidine dihydrochloride (Sigma) procedure. Absorbance was determined by a plate reader (SpectraMax 190) at a wavelength of $450 \mathrm{~nm}$. Plasma BHB concentration was measured by the enzymatic oxidation of BHB to acetoacetate using 3-hydroxybutyrate dehydrogenase (Roche, Mississauga, ON, Canada) followed by determination of reduction of $\mathrm{NAD}^{+}$to $\mathrm{NADH}$ at a wavelength of $340 \mathrm{~nm}$. Commercial kits were used to determine concentrations of plasma nonesterified fatty acids (Wako Chemicals USA Inc., Richmond, VA) and insulin (Coat-a-Count kit, Diagnostic Products Corp., Los Angeles, CA).

\section{Milk Composition}

Milk samples were analyzed for milk fat, CP, lactose, and MUN by mid-infrared spectroscopy (AOAC International, 2002; method 972.16; MilkoScan FTIR 6000, Foss North America, Brampton, ON, Canada) at the Alberta Central Milk Testing Laboratory (Edmonton, AB, Canada). Milk yield and milk composition data from a.m. and p.m. milking were used to calculate the daily milk composition for d 18, 19, and 20, and the data were averaged for one value per cow per period. The ECM yield was calculated according to the equation described by Tyrrell and Reid (1965): ECM = $[0.327 \times$ milk yield $(\mathrm{kg})+12.95 \times$ fat yield $(\mathrm{kg})+7.2$ $\times$ protein yield].

\section{Statistical Analysis}

Data were analyzed using the fit model procedure of JMP (version 11.0, SAS Institute Inc.) according to the following model:

$$
Y_{i j k}=\mu+P_{i}+T_{j}+C_{k}+e_{i j k},
$$

where $Y_{i j k}$ is the dependent variable, $\mu$ is overall mean, $P_{i}$ is fixed effect of period, $T_{j}$ is fixed effect of treatment, $C_{k}$ is the random effect of cows, and $e_{i j k}$ is the residual. Preplanned orthogonal contrasts were used to compare treatment means of high-NFC diets (STA, SUC, and LAC) versus CON, high-disaccharide diets (SUC and LAC) versus STA, and SUC versus LAC. Treatment effects were declared significant at $P \leq 0.05$, and a tendency was declared at $0.05<P \leq 0.10$.

\section{RESULTS}

\section{Feed Intake and Milk Production}

Dry matter intake was higher $(P=0.04)$ for cows fed the high-NFC diets than for those fed the CON diet (Table 2). In addition, cows fed high-disaccharide diets had higher DMI than those fed the STA diet $(P$ $<0.01)$. However, cows fed SUC and LAC diets did not differ.

Milk yield was not different between cows fed the CON diet and high-NFC diets, but yield $(P=0.06)$ and concentration $(P=0.07)$ of milk fat tended to be lower for cows fed high-NFC diets than those fed the $\mathrm{CON}$ diet. The concentration of milk protein was higher $(P=0.02)$ for cows fed high-NFC diets com- 
pared with those fed the CON diet, whereas the yields of milk protein did not differ. In addition, cows fed high-NFC diets had lower MUN concentration than those fed the CON diet $(P<0.01)$. Cows fed highdisaccharide diets tended to have higher $(P=0.06)$ milk yield compared with those fed the STA diet, and they had higher $(P<0.01)$ ECM than those fed the STA diet. Cows fed high-disaccharide diets had greater milk fat yield $(P=0.01)$ and protein yield $(P=0.02)$ and tended to have greater milk protein concentration $(P=0.09)$ compared with those fed the STA diet. Milk and milk component yields did not differ between cows fed the SUC diet and LAC diet, but cows fed the LAC diet tended to have higher milk fat concentration $(P=$ 0.06) than those fed the SUC diet.

\section{Ruminal pH, VFA Profile, and VFA Absorption}

Rumen $\mathrm{pH}$ did not differ between cows fed CON and high-NFC diets (Table 3$)$. Daily minimum $(P=0.03)$ and mean rumen $\mathrm{pH}(P=0.02)$ were lower for cows fed the high-disaccharide diets than for those fed the STA diet. Moreover, the duration that rumen $\mathrm{pH}$ was below 5.8 was longer $(P=0.05)$, and the area that rumen $\mathrm{pH}$ was below 5.8 tended to be greater $(P=0.09)$, for cows fed the high-disaccharide diets compared with those fed the STA diet. However, rumen $\mathrm{pH}$ did not differ between cows fed SUC and LAC diets. In addition, acidosis index was similar across treatments.

The molar proportion of acetate was lower $(P<0.01)$ but that of butyrate was higher $(P<0.01)$ for cows fed
high-NFC diets compared with those fed the CON diet. In addition, cows fed high-NFC diets had lower rumen $\mathrm{NH}_{3}-\mathrm{N}$ concentration $(P<0.01)$ and ratio of acetate to propionate $(P=0.02)$ than those fed the $\mathrm{CON}$ diet. Cows fed high-disaccharide diets had lower molar proportion of acetate $(P=0.03)$ but higher molar proportion of butyrate $(P<0.01)$ compared with those fed the STA diet. The molar proportion of butyrate was higher for cows fed the LAC diet than for those fed the SUC $\operatorname{diet}(P=0.01)$. Total VFA concentration, the molar proportion of propionate, and total VFA absorption rate were not different among all treatments.

\section{Digestibility and Plasma Metabolites}

The apparent total-tract digestibility of DM $(P<$ $0.01)$, OM $(P<0.01)$, starch $(P=0.02)$, and NDF $(P<0.01)$ were lower for cows fed high-NFC diets than for those fed the CON diet (Table 4). In addition, compared with cows fed the STA diet, cows fed highdisaccharide diets had lower DM $(P=0.01)$, OM $(P=$ $0.01)$, and starch $(P=0.03)$ digestibilities but higher sugar digestibility $(P<0.01)$. When comparing cows fed SUC and LAC diets, cows fed the LAC diet had higher total-tract digestibility of DM $(P=0.01)$, OM $(P=0.01)$, starch $(P=0.02)$, and CP $(P<0.01)$, but the digestibility of NDF and sugar was not different between cows fed the SUC and LAC diets.

Plasma glucose, nonesterified fatty acid, BHB, and insulin concentrations were not different among all treatments (Table 5).

Table 2. Effect of increasing dietary NFC with starch, sucrose, or lactose for lactating dairy cows on DMI, milk production, and milk composition $(\mathrm{n}=28)$

\begin{tabular}{|c|c|c|c|c|c|c|c|c|}
\hline \multirow[b]{2}{*}{ Variable } & \multicolumn{4}{|c|}{$\operatorname{Diet}^{1}$} & \multirow[b]{2}{*}{ SEM } & \multicolumn{3}{|c|}{$P$-value ${ }^{2}$} \\
\hline & $\mathrm{CON}$ & STA & SUC & LAC & & 1 & 2 & 3 \\
\hline DMI, kg/d & 26.3 & 26.2 & 27.5 & 27.5 & 0.70 & 0.04 & $<0.01$ & 0.94 \\
\hline \multicolumn{9}{|l|}{ Yield, kg/d } \\
\hline Milk & 37.5 & 36.9 & 38.1 & 37.7 & 1.79 & 0.97 & 0.06 & 0.54 \\
\hline ECM & 39.5 & 38.0 & 39.5 & 39.6 & 1.59 & 0.37 & $<0.01$ & 0.94 \\
\hline Fat & 1.35 & 1.26 & 1.31 & 1.33 & 0.05 & 0.06 & 0.01 & 0.43 \\
\hline $\mathrm{CP}$ & 1.28 & 1.26 & 1.32 & 1.30 & 0.05 & 0.59 & 0.02 & 0.45 \\
\hline Lactose & 1.71 & 1.69 & 1.73 & 1.71 & 0.09 & 0.85 & 0.19 & 0.56 \\
\hline \multicolumn{9}{|c|}{ Milk composition } \\
\hline Fat, $\%$ & 3.65 & 3.51 & 3.54 & 3.63 & 0.10 & 0.07 & 0.31 & 0.06 \\
\hline $\mathrm{CP}, \%$ & 3.46 & 3.48 & 3.51 & 3.50 & 0.05 & 0.02 & 0.09 & 0.55 \\
\hline Lactose, \% & 4.52 & 4.54 & 4.52 & 4.51 & 0.04 & 0.91 & 0.18 & 0.68 \\
\hline MUN, mg/dL & 14.5 & 13.2 & 12.9 & 13.3 & 0.38 & $<0.01$ & 0.67 & 0.20 \\
\hline
\end{tabular}

${ }^{1} \mathrm{CON}=$ control diet $(27 \%$ starch and $4 \%$ sugar on a DM basis); STA $=$ a high-NFC diet in which dietary starch content was increased by replacing beet pulp in the CON diet with corn grain $(32 \%$ starch and $4 \%$ sugar on a DM basis); $\mathrm{SUC}=$ a high-NFC diet in which dietary sugar content was increased by replacing beet pulp in the CON diet with $5.5 \%$ of sucrose (27\% starch and $9 \%$ sugar on a DM basis); LAC = a high-NFC diet in which dietary sugar content was increased by replacing beet pulp in the CON diet with lactose $(27 \%$ starch and $9 \%$ sugar on a DM basis).

${ }^{2} P$-value: $1=$ high-NFC diets (STA, SUC, and LAC) versus CON; $2=$ high-disaccharide diets (SUC and LAC) versus STA; $3=$ SUC versus LAC. 
Table 3. Effect of increasing dietary NFC with starch, sucrose, or lactose for lactating dairy cows on rumen pH, rumen fermentation, and VFA absorption rate $(\mathrm{n}=8$ ruminally cannulated cows)

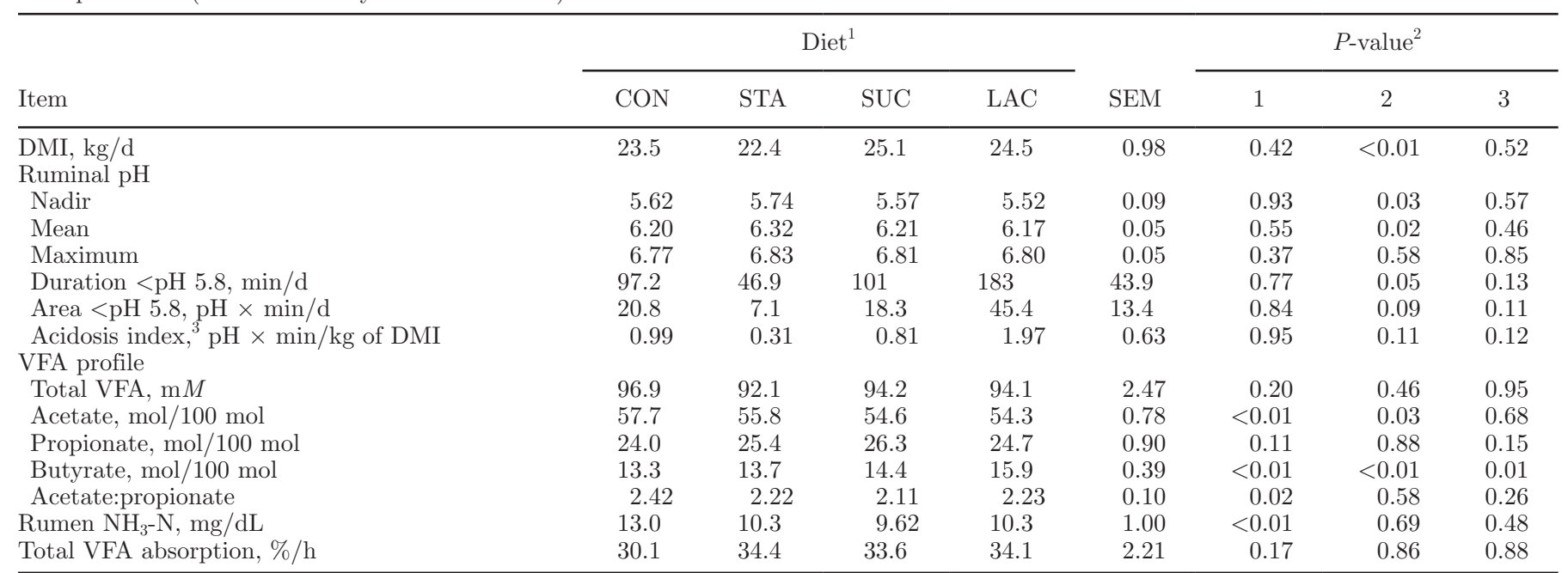

${ }^{1} \mathrm{CON}=$ control diet $(27 \%$ starch and $4 \%$ sugar on a DM basis); STA = a high-NFC diet in which dietary starch content was increased by replacing beet pulp in the CON diet with corn grain (32\% starch and $4 \%$ sugar on a DM basis); SUC = a high-NFC diet in which dietary sugar content was increased by replacing beet pulp in the CON diet with $5.5 \%$ of sucrose ( $27 \%$ starch and $9 \%$ sugar on a DM basis); LAC $=$ a high-NFC diet in which dietary sugar content was increased by replacing beet pulp in the CON diet with lactose (27\% starch and $9 \%$ sugar on a DM basis).

${ }^{2} P$-value: 1 = high-NFC diets (STA, SUC, and LAC) versus CON; $2=$ high-disaccharide diets (SUC and LAC) versus STA; $3=$ SUC versus LAC.

${ }^{3}$ Acidosis index: area under pH 5.8 divided by DMI (Penner et al., 2009a).

\section{DISCUSSION}

Dietary NFC content is often increased in diets for high-producing cows to increase energy intake and maximize milk yield. However, greater rumen fermentation from feeding more NFC may also increase the risk of ruminal acidosis, which potentially can have negative effects on feed intake (Krajcarski-Hunt et al., 2002), health, and production performance (Broderick, 2003; Ferraretto et al., 2013). In the current study, cows were fed low-forage diets (35\% forage and $15.6 \%$ forage
NDF on DM basis) for all treatments, and dietary NFC contents were further increased by replacing beet pulp with corn grain, sucrose, or lactose, respectively, for STA, SUC, and LAC treatments. We found that rumen $\mathrm{NH}_{3}-\mathrm{N}$ and MUN concentrations were lower for cows fed high-NFC diets even if dietary CP content was similar for all experimental diets. These results might indicate more OM fermentation and microbial protein synthesis in the rumen (Nocek and Russell, 1988; Russell et al., 1992) when dietary NFC content increased, resulting in less $\mathrm{NH}_{3}-\mathrm{N}$ concentration in the rumen and less urea

Table 4. Effect of increasing dietary NFC with starch, sucrose, or lactose for lactating dairy cows on apparent total-tract nutrient digestibility $(\mathrm{n}=8$ ruminally cannulated cows)

\begin{tabular}{|c|c|c|c|c|c|c|c|c|}
\hline \multirow{2}{*}{$\begin{array}{l}\text { Digestibility, } \\
\%\end{array}$} & \multicolumn{4}{|c|}{ Diet $^{1}$} & \multirow[b]{2}{*}{ SEM } & \multicolumn{3}{|c|}{$P$-value ${ }^{2}$} \\
\hline & $\mathrm{CON}$ & STA & SUC & LAC & & 1 & 2 & 3 \\
\hline $\mathrm{DM}$ & 67.9 & 64.9 & 57.8 & 63.0 & 1.45 & $<0.01$ & 0.01 & 0.01 \\
\hline $\mathrm{OM}$ & 69.1 & 66.2 & 59.7 & 64.4 & 1.41 & $<0.01$ & 0.01 & 0.01 \\
\hline Starch & 89.1 & 86.0 & 73.7 & 83.2 & 2.70 & 0.02 & 0.03 & 0.02 \\
\hline CP & 64.1 & 66.9 & 59.7 & 68.0 & 2.00 & 0.73 & 0.22 & $<0.01$ \\
\hline $\mathrm{NDF}$ & 43.7 & 35.3 & 34.8 & 32.4 & 2.03 & $<0.01$ & 0.50 & 0.41 \\
\hline Sugar & 92.2 & 89.0 & 93.8 & 95.7 & 1.31 & 0.64 & $<0.01$ & 0.30 \\
\hline
\end{tabular}

${ }^{1} \mathrm{CON}=$ control diet $(27 \%$ starch and $4 \%$ sugar on a DM basis); STA $=$ a high-NFC diet in which dietary starch content was increased by replacing beet pulp in the CON diet with corn grain $(32 \%$ starch and $4 \%$ sugar on a DM basis); $\mathrm{SUC}=$ a high-NFC diet in which dietary sugar content was increased by replacing beet pulp in the CON diet with $5.5 \%$ of sucrose (27\% starch and $9 \%$ sugar on a DM basis); LAC = a high-NFC diet in which dietary sugar content was increased by replacing beet pulp in the CON diet with lactose $(27 \%$ starch and $9 \%$ sugar on a DM basis).

${ }^{2} P$-value: $1=$ high-NFC diets (STA, SUC, and LAC) versus CON; $2=$ high-disaccharide diets (SUC and LAC) versus STA; $3=\mathrm{SUC}$ versus LAC. 
Table 5. Effect of increasing dietary NFC with starch, sucrose, or lactose for lactating dairy cows on plasma metabolite concentrations $(\mathrm{n}=8$ ruminally cannulated cows)

\begin{tabular}{|c|c|c|c|c|c|c|c|c|}
\hline \multirow[b]{2}{*}{ Variable } & \multicolumn{4}{|c|}{ Diet $^{1}$} & \multirow[b]{2}{*}{ SEM } & \multicolumn{3}{|c|}{$P$-value ${ }^{2}$} \\
\hline & $\mathrm{CON}$ & STA & SUC & LAC & & 1 & 2 & 3 \\
\hline Nonesterified fatty acid, $\mathrm{mEq} / \mathrm{L}$ & 37.9 & 36.0 & 42.6 & 41.0 & 3.80 & 0.67 & 0.25 & 0.77 \\
\hline $\mathrm{BHB}, \mathrm{mg} / \mathrm{dL}$ & 10.7 & 9.69 & 10.4 & 11.1 & 1.16 & 0.84 & 0.44 & 0.68 \\
\hline Insulin, $\mu \mathrm{IU} / \mathrm{mL}$ & 7.36 & 9.49 & 9.88 & 8.53 & 1.16 & 0.13 & 0.83 & 0.37 \\
\hline
\end{tabular}

${ }^{1} \mathrm{CON}=$ control diet $(27 \%$ starch and $4 \%$ sugar on a DM basis); STA = a high-NFC diet in which dietary starch content was increased by replacing beet pulp in the CON diet with corn grain (32\% starch and $4 \%$ sugar on a DM basis); SUC = a high-NFC diet in which dietary sugar content was increased by replacing beet pulp in the CON diet with $5.5 \%$ of sucrose $(27 \%$ starch and $9 \%$ sugar on a DM basis); LAC $=$ a high-NFC diet in which dietary sugar content was increased by replacing beet pulp in the CON diet with lactose (27\% starch and $9 \%$ sugar on a DM basis).

${ }^{2} P$-value: $1=$ high-NFC diets (STA, SUC, and LAC) versus CON; $2=$ high-disaccharide diets (SUC and LAC) versus STA; $3=$ SUC versus LAC.

excretion in milk. Even though beet pulp in the CON diet was expected to be less fermentable than corn grain or disaccharides in the rumen, we observed no differences in rumen $\mathrm{pH}$ between $\mathrm{CON}$ and high-NFC diets. Consistent with our findings, Voelker and Allen (2003) did not detect the difference in rumen $\mathrm{pH}$ when they replaced high-moisture corn grain with up to $24 \%$ beet pulp in the diet, which decreased dietary starch content from 34.6 to $18.4 \%$ (DM basis). In addition, it should be noted that the responses in rumen $\mathrm{pH}$ were variable within the high-NFC treatments (STA, SUC, and LAC diets) in the current study. This is probably due to the different fermentation characteristics among NFC sources (Sniffen et al., 1992), and it is necessary to investigate the effects of feeding different types of NFC on rumen fermentation and animal production.

\section{Starch Versus Disaccharides}

Although rates of hydrolysis $(248-1,404 \% / \mathrm{h})$ and fermentation $(264-738 \% / \mathrm{h})$ of sugars were reported to be very rapid (Weisbjerg et al., 1998), previous studies showed that replacing dietary starch with either sucrose (Broderick and Radloff, 2004; Broderick et al., 2008) or lactose (DeFrain et al., 2004) did not decrease rumen $\mathrm{pH}$ in lactating cows. In vitro studies have indicated that feeding sugar could increase molar proportion of butyrate in the rumen (Vallimont et al., 2004; Ribeiro et al., 2005), which was suggested as one possible explanation of no decrease in rumen $\mathrm{pH}$ for animals fed diets in which starch was partially replaced with sugar (Oba, 2011). Because $1 \mathrm{~mol}$ of hexose ferments to $1 \mathrm{~mol}$ of butyrate, but to 2 moles of propionate or acetate, increased butyrate production could decrease proton production compared with acetate or propionate production (Oba, 2011). We found higher butyrate molar proportion for high-disaccharide diets in this study; however, rumen $\mathrm{pH}$ was lower for cows fed high-disaccharide diets compared with those fed the
STA diet. Lower rumen $\mathrm{pH}$ for high-disaccharide treatments might be partly due to greater DMI; for $8 \mathrm{ru}$ minally cannulated cows, high-disaccharide treatments increased DMI by more than $2 \mathrm{~kg} / \mathrm{d}$ compared with the STA treatment. In addition, low-forage diets $(35 \%$ forage and $15.6 \%$ forage NDF on DM basis) were fed to the animals in this study. Therefore, it is possible that the increased DMI of the highly fermentable diets may cause more OM fermentation in the rumen for cows fed high-disaccharide diets, leading to the lower rumen $\mathrm{pH}$ compared with the STA diet. Acidosis index, which indicated the severity of rumen acidosis normalized for DMI, did not differ between high-disaccharide diets and the STA diet. However, the $P$-value for acidosis index was 0.11 , which is close to the tendency, and the lower rumen $\mathrm{pH}$ for high-disaccharide treatments may not be exclusively attributed to greater DMI.

Milk yield tended to be greater for cows fed highdisaccharide diets compared with cows fed the STA diet in this study, leading to the higher milk protein, milk fat, and ECM yield for high-disaccharide diets. Previous studies (Broderick et al., 2008; Penner and Oba, 2009) also found greater milk fat yield for cows fed high-sugar diets. Therefore, although rumen $\mathrm{pH}$ was decreased for high-sugar diets in this study, partially replacing dietary starch with disaccharide did not have negative effects on feed intake and milk production but, in fact, increased DMI, milk, and milk component yields for lactating cows.

Both in vitro (Vallimont et al., 2004) and in vivo (DeFrain et al., 2004) studies have shown that feeding high-sugar diets is often associated with greater butyrate concentration in the rumen. It was suggested that butyrate stimulated ruminal papillae growth and proliferation (Mentschel et al., 2001) and may be a potent modulator of functional changes in ruminal epithelial tissue (Penner et al., 2011). Malhi et al. (2013) reported that the ruminal epithelia growth and absorption capacity of VFA were increased when butyrate was ruminally 
infused in goats. In the current study, we found that high-disaccharide diets increased the molar proportion of butyrate in the rumen compared with the STA diet. However, we did not detect a difference in rumen VFA absorption rate across the treatments. One possibility accounting for the lack of treatment effects on VFA absorption is insufficient sensitivity of the method used to measure rate of VFA absorption in the current study. Penner et al. (2009c) has summarized a few limitations associated with this method, such as temporal increase of rumen osmolarity right after dosing and different fractional rate of absorption between n-valeric acid and other VFA. Another possibility is that the 21-d periods in this study might be too short for the diets to exert significant effects on the ruminal papillae growth and their metabolism to affect VFA absorption. When cows are exposed to a dietary change, a 4- to 8-wk adaptation period is suggested for maximal increases in the ruminal papillae number and size (Dirksen et al., 1985; Bannink et al., 2008). In addition, it is possible that increasing dietary sugar content affected relative proportions of VFA absorption pathways (i.e., passive diffusion or bicarbonate-dependent transport) without affecting overall VFA absorption rate. Chibisa et al. (2015) found that total VFA absorption rate was not different, but $\mathrm{Cl}^{-}$-competitive absorption (bicarbonatedependent transport) of acetate and propionate was increased by partial replacement of dietary starch with lactose. However, this speculation could not be assessed with the methodology in the current study. Therefore, further investigation is needed to improve understanding of the VFA absorption mechanism, particularly for specific effects of sugar fermentation.

Apparent total-tract digestibilities of $\mathrm{DM}$ and $\mathrm{OM}$ were lower for cows fed high-disaccharide diets than for those fed the STA diet. This may be attributed to the higher DMI for the high-disaccharide diets and subsequent greater solid or liquid passage rates (Khalili and Huhtanen, 1991; Sutoh et al., 1996). Greater DMI associated with faster passage rates would generally decrease nutrient digestibility (Tyrrell and Moe, 1975; Colucci et al., 1982). In addition, lower rumen $\mathrm{pH}$ for high-disaccharide diets could affect the growth of cellulolytic bacteria and decrease the fiber digestibility in the rumen (Nagaraja and Titgemeyer, 2007). However, our results on apparent OM digestibility may not be associated with fiber digestibility because NDF digestibility was similar between STA and high-disaccharide diets. Other studies reported that substituting corn grain with sucrose at 4.4 to $4.8 \%$ of dietary DM did not affect total-tract digestibility of any nutrients in lactating dairy cows (Penner and Oba, 2009; Penner et al., 2009b). Reasons for the discrepancy are not clear.
Although apparent total-tract digestibilities of sugar and starch were found lower for cows fed high-disaccharide diets than for those fed the STA diet, the values reported in this study were generally lower than the expected values regardless of treatment. It was noted that contents of sugar $(1.29 \pm 0.62 \%$, mean $\pm \mathrm{SD})$ and starch $(10.8 \pm 4.86 \%$, mean $\pm \mathrm{SD})$ in the fecal samples were relatively high. High starch diets were fed in the current study, and Owens et al. (1986) suggested that the extent of starch digestion decreased when the activity of enzymes, such as amylase and maltase, is limited in the small intestine. However, some previous studies detected over $90 \%$ total-tract starch digestibility when feeding diets with similar starch content as in the current study (Yang and Beauchemin, 2005; Silveira et al., 2007). Yang et al. (2000) and Beauchemin et al. (2001) showed that total-tract starch digestibility increased as the extent of processing increased for steam-rolled and temper-rolled barley, respectively. Therefore, it is possible that rolled barley grain, the main dietary starch source used in this study, was not processed to the optimal extent, resulting in relatively lower totaltract starch digestibility regardless of treatment. In addition, the current study used indigestible NDF as an internal maker to estimate nutrient digestibility, and its accuracy to predict digestibility is affected by diet type (Cochran et al., 1986), which might be another possible reason for the relatively low values of nutrient digestibility in this study.

\section{Sucrose Versus Lactose}

Because of the faster hydrolysis and fermentation rate, previous studies found that ruminal dose of sucrose decreased rumen $\mathrm{pH}$ to a greater extent than lactose (Weisbjerg et al., 1998; Oba et al., 2015). Therefore, we had expected that cows fed the SUC diet would have lower rumen $\mathrm{pH}$ compared with those fed the LAC diet, but this was not observed. One possible reason is that feeding sugars in TMR may have different effects on rumen fermentation and rumen $\mathrm{pH}$ compared with rapid fermentation of sugars from a single dose. Feeding sugars in TMR would sustain their effects over a whole day, whereas a single dose would have strong shortterm effect immediately after the dose.

Because of the expected lower rumen $\mathrm{pH}$ for SUC, we had also expected lower milk fat content for SUC than LAC treatment. In fact, we found that SUC treatment tended to decrease milk fat concentration compared with the LAC diet, but this cannot be attributed to effects of rumen $\mathrm{pH}$ because rumen $\mathrm{pH}$ was not lower for the SUC treatment. Tendency of lower milk fat concentration for the SUC treatment might be related to 
the lower butyrate concentration in the rumen because butyrate is a substrate for de novo fatty acid synthesis (Van Soest, 1994). In addition, we found that cows fed the SUC diet had decreased apparent total-tract digestibility of DM, OM, starch, and CP than those fed the LAC diet. However, we did not find any differences in DMI, milk, and milk component yields between SUC and LAC treatments, which suggested that the differences in rumen fermentation and nutrient digestibility in this study might not be large enough to cause significant effects on milk production.

\section{CONCLUSIONS}

Feeding high-disaccharide diets to lactating dairy cows increased DMI, milk fat, milk protein, and ECM yields compared with the high-starch diet even though rumen $\mathrm{pH}$ was lower for cows fed high-disaccharide diets. The treatment effects on rumen $\mathrm{pH}$ cannot be attributed to VFA absorption rate. For effects of sugar types, some differences in nutrient digestibility and rumen fermentation were observed between cows fed sucrose and lactose, but the differences might not be large enough to affect rumen $\mathrm{pH}$, DMI, and milk yield.

\section{ACKNOWLEDGMENTS}

This study was supported by Alberta Milk (Edmonton, AB, Canada) and Natural Sciences and Engineering Research Council of Canada (Ottawa, ON, Canada). The authors thank Y. Sun, J. Haisan, and A. Ruiz-Sanchez (University of Alberta, Edmonton, AB, Canada) for their assistance with animal handing and sample collections.

\section{REFERENCES}

AOAC International. 2000. Official Methods of Analysis. 17th ed. AOAC Int., Gaithersburg, MD.

AOAC International. 2002. Official Methods of Analysis. 17th ed. AOAC Int., Gaithersburg, MD.

Bannink, A., J. France, S. Lopez, W. J. Gerrits, E. Kebreab, S. Tamminga, and J. Dijkstra. 2008. Modelling the implications of feeding strategy on rumen fermentation and functioning of the rumen wall. Anim. Feed Sci. Technol. 143:3-26.

Beauchemin, K. A., W. Z. Yang, and L. M. Rode. 2001. Effects of barley grain processing on the site and extent of digestion of beef feedlot finishing diets. J. Anim. Sci. 79:1925-1936.

Broderick, G. A. 2003. Effects of varying dietary protein and energy levels on the production of lactating dairy cows. J. Dairy Sci. 86:1370-1381.

Broderick, G. A., N. D. Luchini, S. M. Reynal, G. A. Varga, and V. A. Ishler. 2008. Effect on production of replacing dietary starch with sucrose in lactating dairy cows. J. Dairy Sci. 91:4801-4810.

Broderick, G. A., and W. J. Radloff. 2004. Effect of molasses supplementation on the production of lactating dairy cows fed diets based on alfalfa and corn silage. J. Dairy Sci. 87:2997-3009.
Chamberlain, D. G., S. Robertson, and J. J. Choung. 1993. Sugars versus starch as supplements to grass silage: Effects on ruminal fermentation and the supply of microbial protein to the small intestine, estimated from the urinary excretion of purine derivatives, in sheep. J. Sci. Food Agric. 63:189-194.

Chibisa, G. E., P. Gorka, G. B. Penner, R. Berthiaume, and T. Mutsvangwa. 2015. Effects of partial replacement of dietary starch from barley or corn with lactose on ruminal function, short-chain fatty acid absorption, nitrogen utilization, and production performance of dairy cows. J. Dairy Sci. 98:2627-2640.

Cochran, R. C., D. C. Adams, J. D. Wallace, and M. L. Galyean. 1986. Predicting digestibility of different diets with internal markers: Evaluation of four potential markers. J. Anim. Sci. 63:1476-1483.

Colucci, P. E., L. E. Chase, and P. J. Van Soest. 1982. Feed intake, apparent diet digestibility, and rate of particulate passage in dairy cattle. J. Dairy Sci. 65:1445-1456.

DeFrain, J. M., A. R. Hippen, K. F. Kalscheur, and D. J. Schingoethe. 2004. Feeding lactose increases ruminal butyrate and plasma $\beta$-hydroxybutyrate in lactating dairy cows. J. Dairy Sci. $87: 2486-2494$.

Dirksen, G. U., H. G. Liebich, and E. Mayer. 1985. Adaptive changes of the ruminal mucosa and their functional and clinical significance. Bovine Pract. 20:116-120.

Dubois, M., K. A. Gilles, J. K. Hamilton, P. A. Rebers, and F. Smith. 1956. Colorimetric method for determination of sugars and related substances. Anal. Chem. 28:350-356.

Fawcett, J. K., and J. E. Scott. 1960. A rapid and precise method for the determination of urea. J. Clin. Pathol. 13:156-159.

Ferraretto, L. F., P. M. Crump, and R. D. Shaver. 2013. Effect of cereal grain type and corn grain harvesting and processing methods on intake, digestion, and milk production by dairy cows through a meta-analysis. J. Dairy Sci. 96:533-550.

Hall, M. B. 2009. Analysis of starch, including malt oligosaccharides, in animal feeds: a comparison of methods and a recommended method for AOAC collaborative study. JAOACI 92:42-49.

Heldt, J. S., R. C. Cochran, G. K. Stokka, C. G. Farmer, C. P. Mathis, E. C. Tigemeyer, and T. G. Nagaraja. 1999. Effects of different supplemental sugars and starch fed in combination with degradable intake protein on low-quality forage use by beef steers. J. Anim. Sci. 77:2793-2802.

Khalili, H., and P. Huhtanen. 1991. Sucrose supplements in cattle given grass silage-based diet. 2. Digestion of cell wall carbohydrates. Anim. Feed Sci. Technol. 33:263-273.

Khorasani, G. R., E. K. Okine, and J. J. Kennelly. 1996. Forage source alters nutrient supply to the intestine without influencing milk yield. J. Dairy Sci. 79:862-872.

Kleen, J. L., G. A. Hooijer, J. Rehage, and J. P. Noordhuizen. 2003. Subacute ruminal acidosis (SARA): A review. J. Vet. Med. A Physiol. Pathol. Clin. Med. 50:406-414.

Krajcarski-Hunt, H., J. C. Plaizir, J. P. Walton, R. Spratt, and B. W. McBride. 2002. Short communication: Effect of subacute ruminal acidosis on in situ fiber digestion in lactating dairy cows. J. Dairy Sci. 85:570-573.

Malhi, M., H. Gui, L. Yao, J. R. Aschenbach, G. Gäbel, and Z. Shen. 2013. Increased papillae growth and enhanced short-chain fatty acid absorption in the rumen of goats are associated with transient increases in cyclin D1 expression after ruminal butyrate infusion. J. Dairy Sci. 96:7603-7616.

McCormick, M. E., D. D. Redfearn, J. D. Ward, and D. C. Blouin. 2001. Effect of protein source and soluble carbohydrate addition on rumen fermentation and lactation performance of Holstein cows. J. Dairy Sci. 84:1686-1697.

Mentschel, J., R. Leiser, C. Mülling, C. Pfarrer, and R. Claus. 2001. Butyric acid stimulates rumen mucosa development in the calf by a reduction of apoptosis. Arch. Tierernahr. 55:85-102.

Nagaraja, T. G., and K. F. Lechtenberg. 2007. Acidosis in feedlot cattle. Vet. Clin. North Am. Food Anim. Pract. 23:333-350.

Nagaraja, T. G., and E. C. Titgemeyer. 2007. Ruminal acidosis in beef cattle: The current microbiological and nutritional outlook. J. Dairy Sci. 90(E. Suppl.):E17-E38. 
Nocek, J. E. 1997. Bovine acidosis: Implications on laminitis. J. Dairy Sci. 80:1005-1028.

Nocek, J. E., and J. B. Russell. 1988. Protein and energy as an integrated system: Relationship of ruminal protein and carbohydrate availability to microbial synthesis and milk production. J. Dairy Sci. 71:2070-2107.

NRC. 2001. Nutrient Requirements of Dairy Cattle. 7th rev. ed. Natl. Acad. Sci., Washington, DC.

Oba, M. 2011. Review: Effects of feeding sugars on productivity of lactating dairy cows. Can. J. Anim. Sci. 91:37-46.

Oba, M., J. L. Mewis, and Z. Zhining. 2015. Effects of ruminal doses of sucrose, lactose, and corn starch on ruminal fermentation and expression of genes in ruminal epithelial cells. J. Dairy Sci 98:586-594.

Owens, F. N., R. A. Zinn, and Y. K. Kim. 1986. Limits to starch digestion in the ruminant small intestine. J. Anim. Sci. 63:1634-1648.

Penner, G. B., J. R. Aschenbach, G. Gäbel, and M. Oba. 2009a. Epithelial capacity for the apical uptake of short chain fatty acids is a key determinant for intra-ruminal $\mathrm{pH}$ and the susceptibility to sub-acute ruminal acidosis in sheep. J. Nutr. 139:1714-1720.

Penner, G. B., K. A. Beauchemin, and T. Mutsvangwa. 2006. An evaluation of the accuracy and precision of a stand-alone submersible continuous ruminal $\mathrm{pH}$ measurement system. J. Dairy Sci. 89:2132-2140.

Penner, G. B., L. L. Guan, and M. Oba. 2009b. Effects of feeding Fermenten on ruminal fermentation in lactating Holstein cows fed two dietary sugar concentrations. J. Dairy Sci. 92:1725-1733.

Penner, G. B., and M. Oba. 2009. Increasing dietary sugar concentration may improve dry matter intake, ruminal fermentation, and productivity of dairy cows in the postpartum phase of the transition period. J. Dairy Sci. 92:3341-3353.

Penner, G. B., M. A. Steele, J. R. Aschenbach, and B. W. McBride. 2011. Molecular adaptation of ruminal epithelia to highly fermentable diets. J. Anim. Sci. 89:1108-1119.

Penner, G. B., M. Taniguchi, L. L. Guan, K. A. Beauchemin, and M. Oba. 2009c. Effect of dietary forage to concentrate ratio on volatile fatty acid absorption and the expression of genes related to volatile fatty acid absorption and metabolism in ruminal tissue. J. Dairy Sci. 92:2767-2781

Resende, J. C., Jr., M. N. Pereira, H. Boer, and S. Tamminga. 2006. Comparison of techniques to determine the clearance of ruminal volatile fatty acids. J. Dairy Sci. 89:3096-3106.

Ribeiro, C. V. D. M., S. K. R. Karnati, and M. L. Eastridge. 2005. Biohydrogenation of fatty acids and digestibility of fresh alfalfa or alfalfa hay plus sucrose in continuous culture. J. Dairy Sci. 88:4007-4017

Russell, J. B., J. D. O'Connor, D. G. Fox, P. J. Van Soest, and C. J. Sniffen. 1992. A net carbohydrate and protein system for evaluat- ing cattle diets. I. Ruminal fermentation. J. Anim. Sci. 70:35513561.

Silveira, C., M. Oba, W. Z. Yang, and K. A. Beauchemin. 2007. Selection of barley grain affects ruminal fermentation, starch digestibility, and productivity of lactating dairy cows. J. Dairy Sci. 90:2860-2869.

Sniffen, C. J., J. D. O'Connor, P. J. Van Soest, D. G. Fox, and J. B. Russell. 1992. A net carbohydrate and protein system for evaluating cattle diets: II. Carbohydrate and protein availability. J. Anim. Sci. 70:3562-3577.

Sutoh, M., Y. Obara, and S. Miyamoto. 1996. The effect of sucrose supplementation on kinetics of nitrogen, ruminal propionate and plasma glucose in sheep. J. Agric. Sci. 126:99-105.

Sutton, J. D. 1968. The fermentation of soluble carbohydrates in rumen contents of cows fed diets containing a large proportion of hay. Br. J. Nutr. 22:689-712.

Tyrrell, H., and P. Moe. 1975. Effect of intake on digestive efficiency. J. Dairy Sci. 58:1151-1163.

Tyrrell, H. F., and J. T. Reid. 1965. Prediction of the energy value of cow's milk. J. Dairy Sci. 48:1215-1223.

Uden, P., P. E. Colucci, and P. J. Van Soest. 1980. Investigation of chromium, cerium and cobalt as markers in digesta. Rate of passage studies. J. Sci. Food Agric. 31:625-632.

Vallimont, J. E., F. Bargo, T. W. Cassidy, N. D. Luchini, G. A. Broderick, and G. A. Varga. 2004. Effects of replacing dietary starch with sucrose on ruminal fermentation and nitrogen metabolism in continuous culture. J. Dairy Sci. 87:4221-4229.

Van Soest, P. J. 1994. Nutritional Ecology of the Ruminant. 2nd ed. Cornell Univ. Press, Ithaca, NY.

Van Soest, P. J., J. B. Robertson, and B. A. Lewis. 1991. Methods for dietary fiber, neutral detergent fiber, and nonstarch polysaccharide in relation to animal nutrition. J. Dairy Sci. 74:3583-3597.

Voelker, J. A., and M. S. Allen. 2003. Pelleted beet pulp substituted for high-moisture corn: 3. Effects on ruminal fermentation, $\mathrm{pH}$, and microbial protein efficiency in lactating dairy cows. J. Dairy Sci. 86:3562-3570.

Weisbjerg, M. R., T. Hvelplund, and B. M. Bibby. 1998. Hydrolysis and fermentation rate of glucose, sucrose and lactose in the rumen. Acta Agric. Scand. Anim. Sci. 48:12-18.

Yang, W. Z., and K. A. Beauchemin. 2005. Effects of physically effective fiber on digestion and milk production by dairy cows fed diets based on corn silage. J. Dairy Sci. 88:1090-1098.

Yang, W. Z., K. A. Beauchemin, and L. M. Rode. 2000. Effects of barley grain processing on extent of digestion and milk production of lactating cows. J. Dairy Sci. 83:554-568. 